\title{
Investigation on different Compositions of E-Glass/Epoxy Composite and its application in Leaf Spring
}

\author{
Suhas ${ }^{1}$, Jaimon D. Q. ${ }^{2}$, Hanumanthraya R. ${ }^{3}$, Vaishak N. L , Mahesh B. \\ Davanageri $^{5}$ \\ 1,2.3, 4 Assistant Professors, Department of Mechanical Engineering, Sahyadri College of Engineering and \\ Management, Karnataka, India \\ ${ }^{5}$ Associate Professors, Department of Mechanical Engineering, Sahyadri College of Engineering and \\ Management, Karnataka, India
}

\begin{abstract}
The unique and diverse characteristics of composite materials have increased in many folds. From feather weight rods to high performance aircraft parts, the use fiber reinforced materials have become a compelling asset due to their high strength to weight ratio and high strength to stiffness ratio combined with easy manufacturing methods. The present endeavor is one such attempt to study the mechanical properties of glass fiber reinforced plastic (GFRP) by varying volume percentage. The mechanical properties involved in the study are tensile strength, bending strength and impact strength. The results are compared for different loading conditions and a suitable composition is selected for the fabrication of mono composite leaf spring. The study concluded that the composite leaf spring had induced stresses much lower than that of steel leaf spring and the spring weight was nearly $44 \%$ lower when compared to steel leaf spring.
\end{abstract}

Keywords: Composite, Leaf Spring.

\section{INTRODUCTION}

The recent years have been a witness to automobile industries showing an increased interest in the replacement of steel springs with composite leaf springs due to their heavyweight advantages in the aspects of material design conception and manufacturing methodology. Leaf springs primarily find its applications in suspension systems in order to absorb shock loads in automobiles like light motor vehicles, heavy duty trucks etc. In addition to shock absorbing, it also carries lateral loads, brake torque and driving torque. Mass breeds of automobile industries have started using composite material technology for structural components construction in order to obtain reduction in overall weight without decreasing vehicle performance and reliability.

The suspension leaf spring is one of the potential elements for weight reduction in automobiles as it leads to the reduction of un-sprung weight of automobile. The reduction of un-sprung weight helps in achieving improved ride characteristics and increased fuel efficiency. To meet the need of natural resources conservation, automobile manufacturers are attempting to reduce the weight of vehicles in recent years. The interest in reducing the weight of automobile parts has necessitated the use of composite materials technology as a substitute in material design. The primary function of the Composite structure is to transfer stresses between reinforcing fibers/particulate and to protect them from mechanical and environmental damages. The most commonly used composites are Glass Fiber Reinforced Epoxy Composites. Epoxy resin possesses good resistance against environmental degradation, high adhesive strength and high mechanical properties, high electrical insulation and good chemical and water resistance. The use of reinforcements in the resin embeds increasing load withstanding capability, moderated coefficients of friction, improved wear resistance, better thermal properties and increased mechanical strength[1].

Carbon fibers usually acquire excellent mechanical, thermal and Tribological properties when compared to glass fibers, but the principal advantages of glass fibers are its low cost and high strength. One of the challenges in the use of glass fiber-reinforced polymer (GFRP) composites for primary structures is to avoid the damage proliferation during conditions involving abrasion [2]. Therefore determination of tensile strength, bending strength and impact strength becomes imperative as these properties play a vital role in the behavior of GFRP under different loading and abrasive conditions.

The present scenario mainly focuses on automobile manufacturers where weight reduction of the leaf spring is a prime concern. Rajesh et al. [3] studied the introduction of fiber reinforced plastics(FRP) which made it possible to reduce the weight of machine element without any reduction of the load carrying capacity. Raghavendra et al. [4] concluded that FRP materials have high elastic strain energy storage capacity and high strength-to-weight ratio compared with those of steel and multi-leaf steel springs therefore are being replaced by mono-leaf FRP springs. Patel et al.[5] conducted a study on composite materials which made it possible to reduce the weight of leaf spring without any reduction in load carrying capacity and stiffness. Jadhao et al. [6] 
discussed the manufacturing system of leaf spring using plywood as a mould material; prototype was fabricated as per desired dimension. It was concluded that constant cross section design, which ensures the fiber pass continuously along length direction without interruption, proved to be advantageous to fiber reinforced structure. Shiva et al. [7] conducted experimental investigations on the end joints of a mono composite leaf spring for light vehicle-design and compared those with analytical results. The results were in good agreement. Venkatesan et al. [8] described the design and experimental analysis of composite leaf spring made of glass fiber reinforced polymer. The objective was to compare the load carrying capacity, stiffness and weight savings of composite leaf spring with that of steel leaf spring. A weight reduction of $76.4 \%$ was achieved by using optimized composite leaf spring. Based on the literature cited above the present study is one such attempt to develop a physical and mechanical characterization of a class of composite material with a polymer called Epoxy-Resin as the matrix and glass fiber as the reinforcing material. The potential of composite materials for leaf spring application is investigated through different material characterization tests.

\subsection{Materials}

\section{Experimental Details}

The matrix material used was medium Epoxy resin widely used in industries due to their strong adhesive properties, chemical resistance and toughness. The reinforcement material employed was E-glass which is a popular fiber primarily made up of silica oxide, along with oxides of aluminum, boron, calcium and other compounds. The hardener HY951 is used in the proportion of 1:10. The choice of hardener is governed by the curing temperature and pot life. The experimentation includes fabrication and testing of different $\%$ by volume of E-Glass/Epoxy. The composite leaf spring is fabricated using best composition of E-glass/Epoxy. The details of the material combination and percentage are given in Table 1.

\section{Table 1- Details of samples prepared}

\begin{tabular}{lclc}
\hline Matrix & Volume (\%) & Reinforcement & Volume (\%) \\
\hline Epoxy & 50 & Glass fiber & 50 \\
Epoxy & 60 & Glass fiber & 40 \\
Epoxy & 70 & Glass fiber & 30 \\
\hline
\end{tabular}

\subsection{Fabrication}

The glass/Epoxy composite is fabricated using simple hand layup technique. The procedure consists of placing the glass fibers, layer by layer and applying liquid epoxy mixed with hardener on the glass fibers in order to form a solid network cross-linked polymer. The layup assembly is pressed with the help of roller so that excess air between the layers is expelled out. The laminate is cured at ambient conditions for a period of about 24hrs. The laminate is prepared for three different compositions of E-glass/Epoxy with a size of $300 \mathrm{~mm} \times 300 \mathrm{~mm} \times 3 \mathrm{~mm}$.

\section{Experimentation}

The fabrication involves three different compositions of composites where the composite plates are cut down according to the ASTM standards in order to carry out tensile, flexural and impact test on each specimen.

\subsection{Plan of Experiments for conducting tests}

Tensile test, 3-point bending test and the impact test is performed in accordance with ASTM D3039, ASTM D790 and ASTM E32 standards. ASTM standards for the above stated tests are given below.

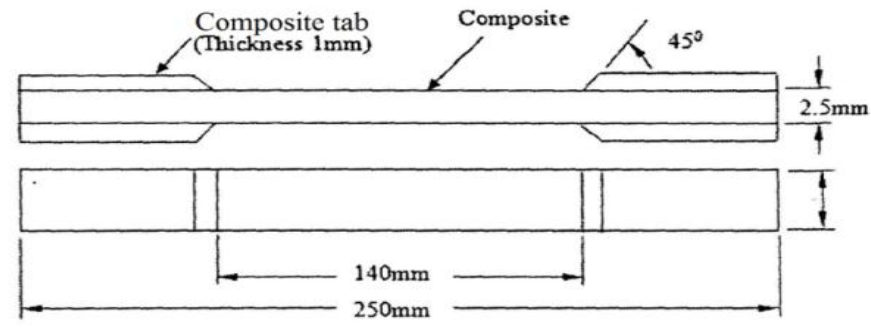

Fig.1: Tensile test specimen as per ASTM D3039 standards. 


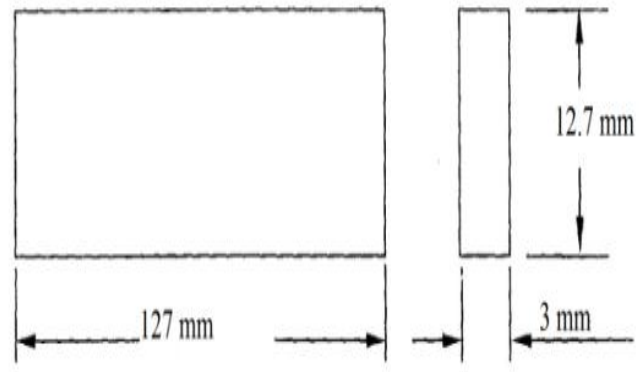

Fig.2:Dimensions of flexural test under ASTM standard D790

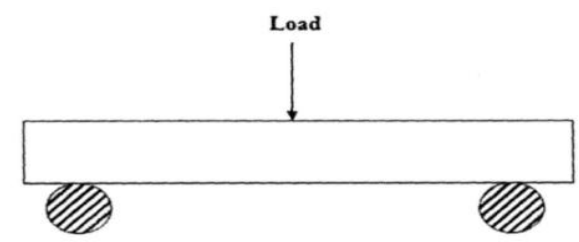

Fig.3: Three-point flexural bending specimens as per ASTM standard D790

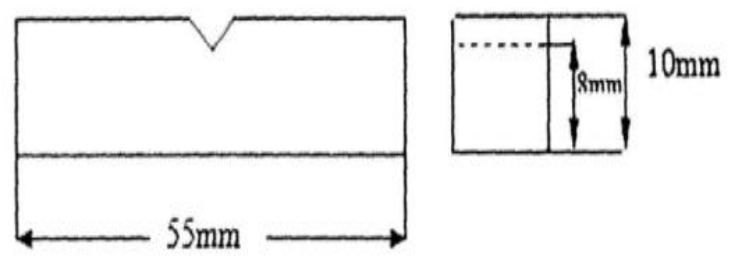

Fig.4: Charpy impact test specimens as per ASTM E32Standards

Tensile test and3-point bending tests are carried out in accordance with ASTM D3039 and ASTM D790 standards respectively under displacement control using an UTM/E-40 with resolution of the piston movement of $0.01 \mathrm{~mm}$.Charpy impact test is performed according to the specification of the ASTM E32 standards using impact test machine.

\subsection{Fabrication of mono composite leaf spring}

After carrying out the tensile, flexural and impact test for three different compositions, the fabrication of composite mono leaf spring is done based on the best composition of E-glass/Epoxy. The mold is fabricated as per desired dimensions which are given in table 2 .

Table 2- Dimensions of the composite leaf spring

\begin{tabular}{cc}
\hline Dimensions & Value $(\mathbf{m m})$ \\
\hline Arc length & 1070 \\
Length of mould & 990 \\
Width & 50 \\
Arc height at axle & 165
\end{tabular}

\subsection{Testing of Steel and Composite Mono Leaf Spring}

The steel and composite leaf springs are tested in the Leaf spring test rig. Figs. 5 \& 6show the experimental setup, both steel and composite leaf springs are tested according to standard procedures recommended by SAE. In a test rig, the plunger is moved up to desired height so that fixture can be fixed and testing can be done. Leaf spring is mounted with the help of fixture, the load is applied gradually and deflections are recorded. The load is applied at the centre of spring and the vertical deflection of the spring centre is recorded with gradually varying load. The spring is loaded from zero to prescribed maximum deflection which gives load v/s displacement curve. 


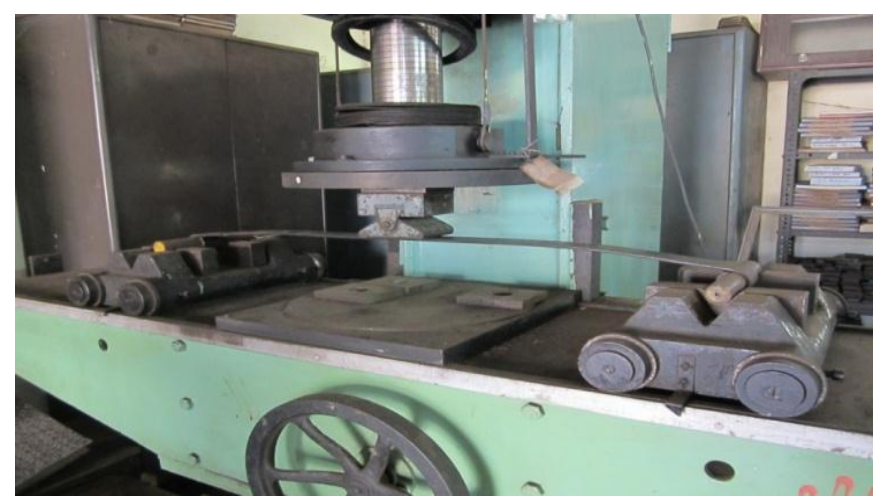

Fig. 5: Testing of Steel leaf spring.

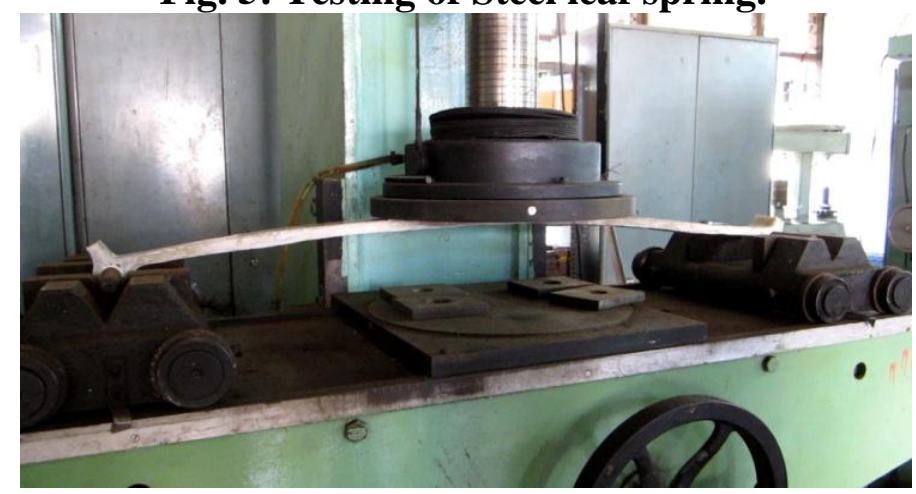

Fig. 6:Testing ofE-glass/Epoxy Composite leaf spring.

\section{Results And Discussions}

In this study, the tensile, flexural and impact tests were carried out on E-glass/Epoxy composite to analyze the effect of different percentage of E-Glass/Epoxy on tensile, bending and impact strength. The tests were carried out for three different cases, namely 50:50\%, 40:60\% and 30:70\% by volume of E-glass/Epoxy.

\subsection{Tensile Test}

Tensile testing, also known as tension testing, is a fundamental materials science test in which a sample is subjected to a controlled tension until failure. The results from the test are commonly used to select a material for an application, for quality control, and to predict how a material will react under different forces. The tensile test is carried out for three different cases. Graph shows the results for three different series of E-glass/Epoxy.

$>$ Series 1- 50:50\% by volume of E-glass/Epoxy

$>$ Series2- 40:60\% by volume of E-glass/Epoxy

$>$ Series3- 30:70\% by volume of E-glass/Epoxy

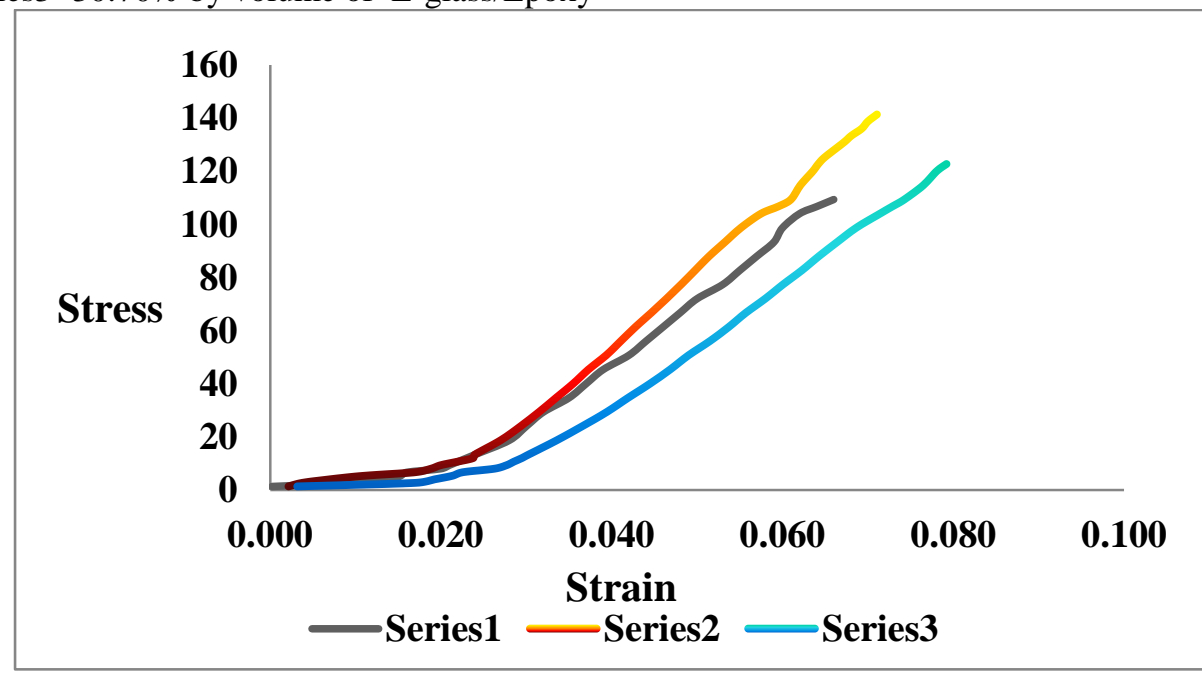

Fig. 7: Comparison of tensile strength for different Composites. 
From the graph, it is clear that 40:60\% by volume of E-glass/Epoxy has maximum yield stress and even ultimate stress and also tensile strength for 40:60\% of E-glass/Epoxy is higher as compared to other two volume percentages.

\subsection{Flexural Test}

Flexural strength is the ability of the material to withstand bending forces applied perpendicular to its longitudinal axis. The stresses induced by the flexural load are a combination of compressive and tensile stresses. Flexural test provides the determination of maximum load bearing capacity of the materials at the one set of plastic deformation of the composites. From this ultimate flexural stress and flexural strain are computed. The bending test is carried out for different volume percentage of E-glass/Epoxy composites. Graph shows the results for three different series of E-glass/epoxy.

$>$ Series 1- 50:50\% by volume of E-glass/Epoxy

$>$ Series2- 40:60\% by volume of E-glass/Epoxy

$>$ Series3- 30:70\% by volume of E-glass/Epoxy

From the graph, it is clear that, volume percentage of 40:60\% of E-glass/Epoxy has the highest bending strength as compared to other two volume percentages.

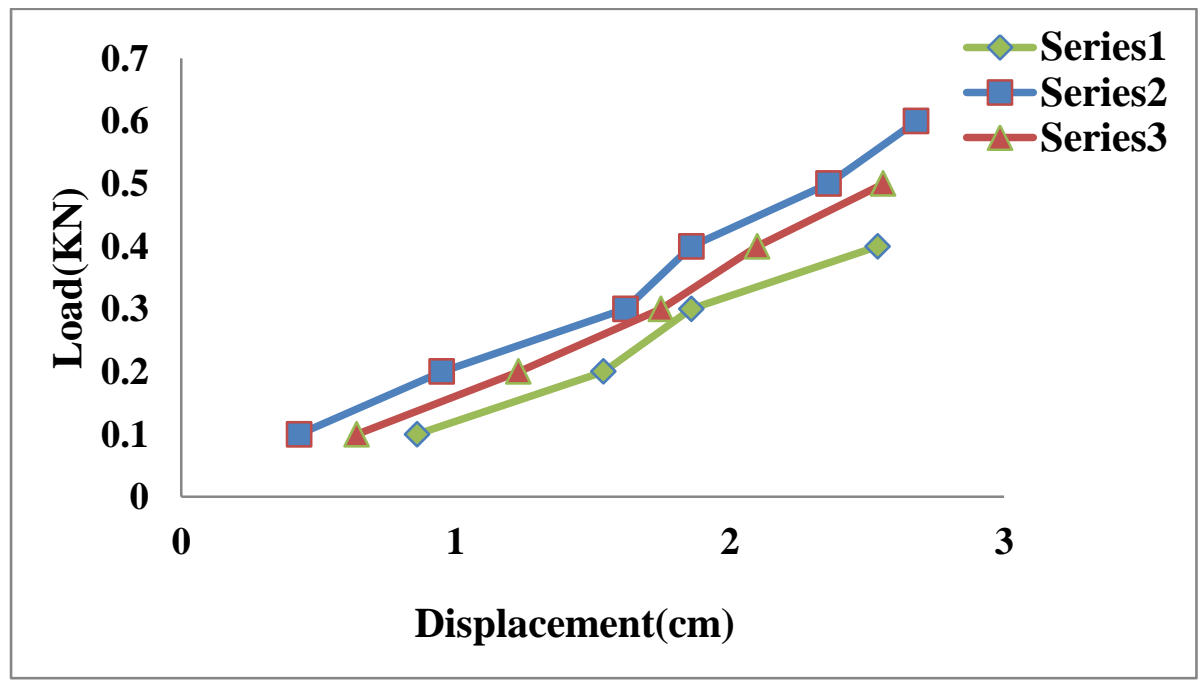

Fig. 8: Comparison of bending strength for different composites.

\subsection{Impact Test}

Impact tests are used for studying the toughness of material. A material's toughness is a factor of its ability to absorb energy during plastic deformation. Brittle materials have low toughness as a result of the small amount of plastic deformation that they can endure. The impact value of a material can also change with temperature. Generally, at lower temperatures, the impact energy of a material is decreased. The size of the specimen may also affect the value of the Izod impact test because it may allow a different number of imperfections in the material, which can act as stress risers and lower the impact energy. Impact strength is obtained by dividing the energy absorbed by the cross sectional area of the specimen under the crack tip. Variation of the impact energy along and across the laminates for three different compositions of composites is as shown in fig. 9 . 


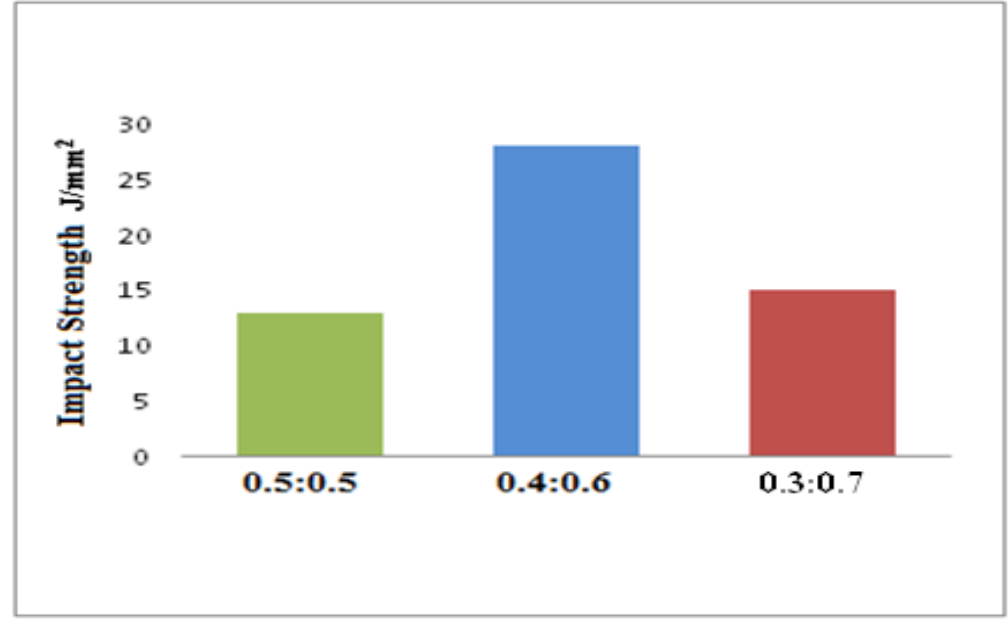

Fig. 9: Impact strength for different composites.

The above tests characterize the fact that E-glass/Epoxy of 40:60\% volume yielded highest Tensile, Flexural and Impact strength thus in implementing the same composition for the fabrication of the Mono composite Leaf spring.

\subsection{Static Load Test}

The primary concern behind conducting a Static load test lies in determining the performance characteristics of a Steel leaf spring and a composite leaf spring. The performance characters include load carrying capacity and weight comparison.

The static load test involves direct pile head displacement in the response to a physically applied test load. It is the most fundamental form of pile load test and is considered as the bench-mark of pile performance. Static load test is carried out for both Steel and composite leaf spring and the responses are shown in Fig. 10. These Figures show a similar trend in variation with increase in displacement with increasing load. But the difference lies in the load carrying capacity which is close to $800(\mathrm{~N})$ in Steel leaf spring and $1000(\mathrm{~N})$ in composite leaf springs. This gives a clear perception about the ability of load carrying capacity in composite materials over conventional metals. However the manufacturing method of the laminates may also play a significant role in composite material strength behavior, because at certain conditions some random behavior was observed which may be particularly due to presence of some voids or other manufacturing defects. These defects may also cause sudden excessive damage while machining, which may ultimately result in drastic reduction in strength of the laminate.

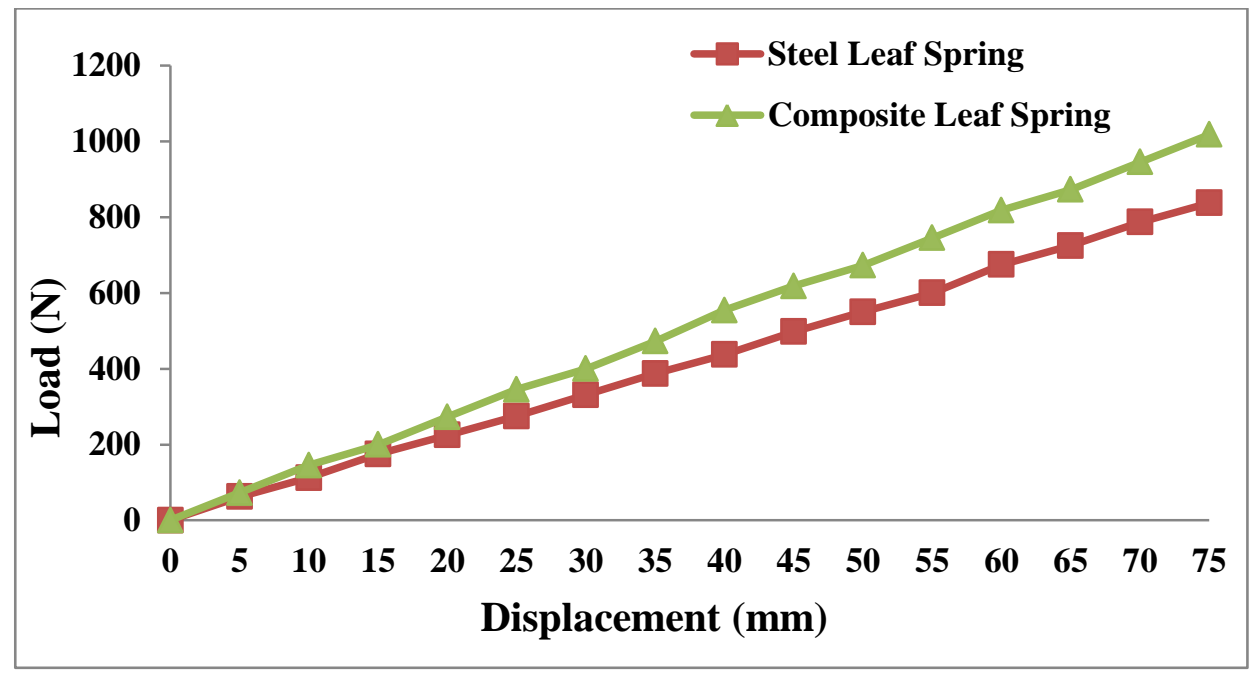

Fig. 10: Load deflection curve for steel leaf spring and composite leaf spring. 


\subsection{Comparison results of load and weight}

After conducting tests, the composite leaf spring results are compared with the steel leaf spring and the comparison is made based on static load carrying capacity and weight, which are tabulated in table 1 and 2 .

\section{Table 3- Comparison of static load carrying capacity.}

\begin{tabular}{ccc}
\hline Leaf Spring & Steel & Composite \\
Static load $(\mathbf{N})$ & 804.4 & 1010.4 \\
\hline
\end{tabular}

Table 4- Weight comparison.

\begin{tabular}{lcc}
\hline Leaf Spring & Steel & Composite \\
Weight $(\mathbf{k g})$ & 3.25 & 1.8 \\
\hline
\end{tabular}

From Tables $3 \& 4$, it is clear that the Composite mono leaf spring reduces the weight by $44.6 \%$ for EGlass/Epoxy over conventional leaf spring. The reduction of $80 \%$ weight is achieved by replacing conventional steel spring with an optimally designed composite mono-leaf spring.

\section{Conclusions}

The experimental investigations conducted on E glass/Epoxy Resin hybrid composites lead to the following conclusions.

$>$ For the compositions of 50:50\%, 40:60\%, 30:70\% by volume of E-glass/Epoxy, 40:60\% composition yielded maximum tensile strength, impact strength and flexural strength.

$>$ The entire fabrication of composite leaf spring was done with 40:60\% of E-Glass/Epoxy composition.

$>$ A comparative study made between composite and steel leaf springs with respect to weight and strength showed that composite leaf spring has more load carrying capacity and is lighter compared to Steel leaf spring.

$>$ The study demonstrated that composites can be used for leaf springs in light weight vehicles which meet the requirements together with substantial weight savings.

\section{Acknowledgement}

The authors express their sincere thanks and gratitude to Mr. Sadanand Salian, General Manager (QMS), Lamina Suspension Products Ltd. Mangalore for providing necessary testing equipments to carry out the present research work.

\section{References}

[1] N. Chand, A. Naik, S. Neogi. Three-body abrasive wear of short glass fiber polyester composite. Wear, 242, 38-46, 2000.

[2] J. Bijwe, S. Awtade, A. Ghosh. Influence of orientation and volume fraction of Aramid fabric on abrasive wear performance of polyethersulfone composites. Wear, 260, 401-411, 2006.

[3]. Dakshraj and Rajesh Satankar. Review of Researches on Leaf Spring Regarding Use of Composite Material and various methods for Predicting Fatigue Life, IJCRR,4, Jan.2012.

[4] M. Raghavedra, Syed Alta fHussain, V. Pandurangadu and K. PalaniKumar. Modeling and analysis of laminated composite leaf spring under the static load condition by using FEM, International journal of modern engineering research,2(4), 1875-1879 , JulyAug.2011.

[5] Vinkel Arora, Gian Bhushan and M.L. Aggarwal. Eye design analysis of single leaf spring in automotive vehicles using CAE tools, International journal of applied engineering and technology, 1(1),88-97, 2011.

[5] S. K. Patel, R. Jain, and V. Gandhi.A Review of Effect of Material on Fatigue Life of Leaf Spring. VSRD International journal of mechanical, automobile and production engineering, 2(4), 161-165, 2012.

[6] K. K. Jadhao and DR. R.S Dalu. Experimental investigation and numerical analysis of composite leaf spring, International journal of engineering science and technology, 3(6), 2011.

[7] R. Shiva and S. Vijayarangan. Mono composite leaf spring for light vehicle-design, end joint analysis and testing, Journal of Material science, 12(3), 2006.

[8] M. Venkatesan and D.Helmen Devaraj. Design and Analysis of Composite Leaf Spring in Light Vehicle International Journal of Modern Engineering Research (IJMER).2(1),213-218, Jan-Feb 2012.

[9] Rajendran and Vijayarangan, "Optimal design of a composite leaf spring using genetic algorithms", July 2000. 